\title{
XLII. Note on a system of imaginaries
}

\section{A. Cayley}

To cite this article: A. Cayley (1847) XLII. Note on a system of imaginaries, Philosophical Magazine Series 3, 30:201, 257-258, DOI: 10.1080/14786444708645686

To link to this article: http://dx.doi.org/10.1080/14786444708645686

册 Published online: 30 Apr 2009.

Submit your article to this journal 정

Џll Article views: 4

Q View related articles ¿

4 Citing articles: 2 View citing articles $\square$ 
Mr. A. Cayley's Note on a System of Imaginaries. 257

woulu amount to 5.896 grains. In some other specimens of urine which I examined there was however no approach to this quantity of phosphorus in an moxidized state, and as the mode of analysis employed in these preliminary experiments was not the most accurate, I intend to make the determination of the quantity of phosphorus the subject of further experiments.

The only opportunity I have had of examining urine in a diseased state, was a portion obtained from a patient suffering from diabetes mellitus. As might have been anticipated from the character of this disease, the amount of sulphur which the urine contained in an unoxidized state, was considerably greater (by one-fourth) than in healthy urine.

The diabetic urine bad a specific gravity of 1046 .

Of this urine 1046 grains, precipitated with nitrate of barytes, gave-

4.308 grains sulphate of barytes $=1.479$ grain $\mathrm{SO}_{3}=0.592$ grain $\mathrm{S}$.

After the precipitation of the sulphuric acid by baryta, the urine was evaporated down with nitric acid, mixed with nitre and deflagrated. An excess of nitrate of barytes having been used to precipitate the sulphuric acid, there remained on treating the fused mass with dilute nitric acid, an insoluble residue of sulphate of barytes, the sulphuric acid of which had been derived from the oxidation of the sulphur by the nitre; the sulphate of barytes amounted to

1.837 grain $=0.629$ grain sulphuric acid $=0.251$ grain sulphur, or 0.024 per cent., whilst in healthy urine the sulphur in this state never exceeded 0.018 per cent.

XLII. Note on a System of Imaginaries. By A. CAYLEY*.

THE octuple system of imaginary quantities, $i_{1}, i_{2}, i_{3}, i_{4}, i_{5}$, $i_{6}, i_{7}$, which $\mathbf{I}$ mentioned in a former paper, (and the conditions for the combination of which are contained in the symbols

$$
123,246,374,145,275,365,167
$$

$i . e$. in the formulæ

$$
\begin{aligned}
& i_{2} i_{3}=i_{1}, i_{3} i_{1}=i_{2}, i_{1} i_{2}=i_{3}, \\
& i_{3} i_{2}=-i_{1}, i_{1} i_{3}=-i_{2}, i_{2} i_{1}=-i_{3},
\end{aligned}
$$

with corresponding formulæ for the other triplets $i_{2}, i_{4}, i_{6} \& \mathrm{c}$. ) possesses the following property; namely, if $i_{\alpha}, i_{\beta}, i_{\gamma}$ be any

* Communicated by the Author.

Phil. Mag. S. 3. Vol. 30. No. 201. April 1847. 
three of the seven quantities which do not form a triplet, then Thus, for instance,

$$
\left(i_{\alpha} i_{\beta}\right) \cdot i_{\gamma}=-i_{\alpha} \cdot\left(i_{\beta} i_{\gamma}\right) \text {. }
$$

but

$$
\begin{gathered}
\left(i_{3} i_{4}\right), i_{5}=-i_{7} . i_{5}=-i_{2} ; \\
i_{3}\left(i_{4} i_{5}\right)=i_{3}: i_{1}=i_{2},
\end{gathered}
$$

and similarly for any other such combination. When $i_{\infty}, i_{6}, i_{\gamma}$ form a triplet, the two products are equal, and reduce themselves each to -1 , or each to +1 , according to the order of the three quantities forming the triplet. Hence in the octuple system in question neither the commutative nor the distributive law holds, which is a still wider departure from the laws of ordinary algebra than that which is presented by Sir Wm. Hamilton's quaternions.

I may mention, that a system of coefficients, which I have obtained for the rectangular transformation of coordinates in $n$ dimensions (Crelle, t. xxxii. Sur quelques propriétés des Déterminans gauches), does not appear to be at all connected with any system of imaginary quantities, though coinciding in the case of $n=3$ with those mentioned in my paper "On Certain Results relating to Quaternions," Phil. Mag. Feb. 1845.

58 Chancery Lane, March 2, 1847.

\section{On Gun-Cotton.}

$B y$ E. F. Teschemacher, Esq.*

$\mathrm{N}$ consequence of the discovery by Professor Schönbein of 1 gun-cotton, and of the possibility of its substitution in many cases for gunpowder, I have been induced to enter into an examination of the mode of its formation and of its synthetical composition, principally with a view of ascertaining how far it would be likely to affect an important branch of trade-the production and value of saltpetre and nitrate of soda. The examination was not commenced with the view of publishing it, but some of the facts brought to light appeared to possess sufficient interest to lay before the Society. $I$ must premise that the experiments relate only to the guncotton prepared by the process recommended by Mr. T. Taylor. Equal measures of nitric acid of sp. gr. 1·509, and of sulphuric acid sp. gr. $1 \cdot 840$, were mixed together, and constituted (No. 1) the acids used in these experiments. I dried 50 grs. of South American cotton (from La Guayra) over a water-bath, and found the cotton gave off 3.40 grs. of hygrometric water. The 46.60 grs. of cotton which remained after drying, I steeped in $487 \frac{1}{2}$ grs. of the mixed acids No. 1 ; the 1846.

* Communicated by the Chemical Society; having been read Nov. 2 , 